\section{Parental presence in the implementation of atraumatic care during children's hospitalization}

\section{Alvionita Handayani, Novy Helena Catharina Daulima}

Faculty of Nursing, Universitas Indonesia

\begin{abstract}
Hospitalization requires children to adapt to various difficult conditions, such as treatments, health personnel, and separation from their families, especially their parents. Separation from parents often causes significant emotional changes in children like anxiety, which could trigger the trauma of hospitalization in both the short and long terms. The study used a qualitative research method with a descriptive phenomenology study approach. It was conducted in the Child Care Room with 11 participants. Data analysis was performed using Creswell thematic analysis. The study produced three themes: i) nurses support the presence of parents during children's hospitalization; ii) parental presence is the main source of coping for children during hospitalization; iii) Parents have a role in fulfilling the children's psychological needs during hospitalization.
\end{abstract}

\section{Introduction}

Data on inpatient epidemiological studies show that the rate of hospitalization of pediatric patients is still high in Indonesia. In $2015,30.6 \%$ of the 82.85 million children aged 0-17 years in Indonesia experienced health problems, and $8.38 \%$ of them went through hospitalization. ${ }^{1}$

Hospitalization is a crisis condition for every child. While undergoing hospitalization, the children were not only required to adapt to their illnesses but also to environments different from their homes. ${ }^{2-4}$ Hospitalization requires children to adapt to various difficult conditions, such as treatment, health personnel, and separation from their family, especially parents. $3,5,6$ Separation from parents often causes significant emotional changes in children due to feelings of loss. ${ }^{7}$

The children's limited skills in adapting to hospitalization conditions have often made it impossible for them to cope with the anxiety they feel, triggering the trauma of hospitalization, both in the short and long terms. ${ }^{3}$ Hospitalization trauma leads to various reactions in children, such as crying, panic attack, refusal to eat, hyperactivity, and self-alienation, which make it difficult for the health worker to approach them. ${ }^{8}$

Left unaddressed, hospitalization trauma can trigger various psychological disorders in children. Sukhodolsky's research adds that children's trauma during hospitalization can lead to aggression. ${ }^{9}$ Such aggression may be a defense mechanism against the condition due to the fears and threats they feel. If it is not overcome well, aggression can cause developmental mental disorders in children. ${ }^{3}$ Thus, to overcome and prevent that condition, it is necessary to have a parent present as the nearest person to the child during hospitalization. The parental presence will reduce stress and put the child at ease. ${ }^{8}$

One of the principles of atraumatic care is family-centered care. Family-centered care supports the round-the-clock presence and participation of parents in the care for hospitalized children. ${ }^{6}$ Family-centered care during hospitalization can provide many benefits, such as increasing the satisfaction of family and patients, improving effective communication between health workers and families, a better understanding of diseases, better coordination in care and the planning of follow-up visits, improving patient safety, and increasing work satisfaction among health workers. ${ }^{10}$

Parents' perceptions of the application of atraumatic care for the hospitalization of children has been widely studied. However, there is no study yet that focuses on the experiences of pediatric patients in regard to parental presence during hospitalization. Through the exploration of children's experience with parental presence during hospitalization, this study will provide a clear picture of the current phenomenon.

\section{Materials and Methods}

\section{Study population}

This research was conducted in a pediatric ward in one top hospital in Jakarta. This care room has applied the principle of atraumatic care to pediatric patients. Moreover, atraumatic care has become the initial competence for every nurse (novice) who is assigned to the pediatric room.

The participants were pediatric patients undergoing hospitalization in the infectious and non-infectious treatment rooms. Participants in this study were selected through a purposive sampling technique. The following were the participant inclusion criteria in this study: children of school age (7 years to 12 years), children with the green
Correspondence: Novy Helena Catharina Daulima, Mental Health Nursing Department, Faculty of Nursing, Universitas Indonesia, Jalan Prof. Dr. Bahder Djohan, Kampus UI Depok, West Java, 16424 Indonesia.

Tel.: +6221.78849120 - Fax: +6221.7864124

E-mail: novi_hc@ui.ac.id

Key words: Parental presence; atraumatic care; hospitalization

Acknowledgments: We would like to thank all participants who were always full of enthusiasm in following this research process to the end.

Funding: The work was supported by Hibah PITTA B 2019, funded by DRPM Universitas Indonesia 2019 (No. NKB-0497/UN2.R3.1/ HKP.05.00/2019)

Contributions: AH: data collection, manuscript writing, data analysis; NHCD: data analysis, manuscript reviewing.

Ethical approval: This research has received ethical approval by the Medical Research Ethics Committee of the Faculty of Medicine Universitas Indonesia - Dr. Cipto Mangunkusumo Hospital Jakarta (No. ND257.UN2.F1/ETIK/PPM.00.02/2019).

Conflict of interest: The authors declare no potential conflict of interest.

This work is licensed under a Creative Commons Attribution NonCommercial 4.0 License (CC BY-NC 4.0).

(C) Copyright: the Author(s), 2020

Licensee PAGEPress, Italy

Pediatric Reports 2020; 12(s1):8693

doi:10.4081/pr.2020.8693

status of NEWS (Nursing Early Warning Score), children who can speak fluently, children who can speak Indonesian, and children hospitalized for $\geq 3$ days.

\section{Design}

This research was conducted using qualitative research methods along with the descriptive phenomenology study approach. The qualitative method was chosen to understand children's experience with the presence of parents in the implementation of atraumatic care during hospitalization. The study was carried out by exploring the information and experiences of the child patient.

\section{Data collection and analysis}

In this study, researchers used data collection tools, such as interview guidelines, field notes, and recorders. Some equipment, 
like drawing tools, coloring tools, storybooks, and children's playthings like cards and toys help reduce anxiety and engage the children. ${ }^{11}$ The process of analyzing data in this study followed the thematic qualitative analysis method. Each interview result was carried out by the following processes: data transcribing, verbatim checking, data coding, reassembling, data interpreting, and concluding. 12

\section{Ethical aspects}

This research has received ethical approval by the Medical Research Ethics Committee of FKUI-RSCM. The research began when the researcher got the consent of the participants' parents. Every participant and parent had the right to withdraw at any time without any sanctions. During the interview process, parents are allowed to accompany participants but are not allowed to provide answers to any question directed to the child by the researcher.

\section{Results}

There were 11 participants in this study. Participants consisted of 8 females and 3 males with ages ranging from 9 years to 11 years and 8 months. The education of all participants was elementary school. The duration of hospitalization for each participant ranged from 4 days to 22 days. There are 4 of 11 participants who had undergone their second hospitalization in the treatment room, while others were new patients in the treatment room. Most of the participants medical diagnoses were cancer and chronic kidney disease.

Based on the thematic analysis, there were three themes found in the research results. The following are the three themes of the research results: i) nurses support the presence of parents during children's hospitalization; ii) the parental presence is the main source of coping for children during hospitalization; iii) parents have a role in fulfilling children's psychological needs during hospitalization.

\section{Nurses support the presence of parents during children's hospitalization}

The results of the first theme analysis are formed based on the description of two categories. The first category is that the nurse allowed children to be accompanied by their parents. Participants in this study recounted that during their hospitalization, nurses always allowed them to be accompanied by their parents. The nurses' actions were assumed by participants to be one form of the nurses' kindness towards partic- ipants. Here are the expressions of some participants.

"The nurse allowed my mom accompanied me, the nurse is kind." (P1)

"Hmm ... It should not be both (of the parents) that can accompany me; it should be only one of them. But the nurse said just do it smartly." (P3)

"You can. It should not be allowed. (In fact, it) can. The nurse is kind.... " (P6)

The second category is that there is no limitation in waiting time for parents. Participants shared that parents can accompany their children at any time to minimize the children's sense of loss towards their families. The following are the expressions of some participants.

"Here beside me, taking care (of me) every day...." (P8)

"Yes, it was allowed by the nurse if mom and dad are here, it's okay all day too...." (P10)

\section{Parental presence is the main source of coping for children during hospitalization}

The second theme demonstrates 3 categories. The first category is that the children need parental presence during invasive procedures. Participants in this study recounted that the presence of parents during invasive procedures made them feel not alone so that their fear was felt to diminish. During invasive procedures, parents created some distractions through calming speech, touch, or hugs. The children also recounted that every distraction created by a nurse could not give them as much comfort as that created by their parents. The following are the expressions of some participants:

"Mom was there with me and turned on the video when the nurse installed the infusion again, then mom was behind me, hugging me. Hm... So I was happy." (P2)

"The nurse said that I have to take a deep breath if I don't want to feel pain, but it didn't work at all. I just needed my mom." (P2)

"If father was not around when I was to be injected, I would have cried..." (P5)

The second category is that the presence of parents provides a safe and comfortable feeling for children. The presence of parents as the closest family members of children can make children feel safe and comfortable during the hospitalization. Parents are the first people to whom participants complain about every condition they feel. This fact was revealed by the participants as follows.
"When installing infusion, mom and father can accompany me so I am not alone." (P1)

"Mama, hold my eyes so I will not be afraid." (P5)

"During my illness, I hold my father. So I am calm if my father is there... "(P6)

"No, my mother must be there. If there is no mother, I am afraid something will happen." (P9)

The third category is the presence of parents as entertainers to relieve the children's boredom. Participants shared that the presence of parents is entertaining while they are undergoing treatment. The limitation in the activities the children can engage in when they are ill causes boredom. Parents' presence makes children feel they have friends to share stories and play with so that the feeling of boredom is reduced. The following are the expressions of some participants.

"Father and mother usually play and entertain me...." (P6)

"Well ... if father is not here, who will I talk to? My father is the only person who likes to talk to me." (P7)

"I'll feel so alone if there's no mom and father....” (P10)

\section{Parents have a role in fulfilling children's psychological needs during hospitalization}

The results of the third theme analysis are formed in the description of the two categories. The first category is that parents help the process of childcare. In this category, the participants shared that during their hospitalization, their parents' presence was very important because the parents not only accompanied them but also participated in their treatment process. The children feel that their parents' presence is helpful for them in every condition. The following are the expressions of several participants.

"If I am vomiting, then mother always helps....” (P3)

"Every 4 hours, the nurse gives me pain medication, later I will drink it with mom's help." (P4)

"It's better there is mom; she is taking care of me. If I have a fever, she compresses." ( $\mathrm{P} 7)$

"Dad is always beside me, so I don't need to worry at all; sometimes, dad also checks my temperature and my blood pressure." (P5)

The last category on this theme is that parents help with children's psychological needs. Participants shared that with the 
presence of parents, the basic needs of children, such as eating, personal hygiene, and resting, can be fulfilled. Participants concluded that in the fulfillment of their psychological needs, it was the parents who played the most important role such that participants felt very dependent on parents regarding the fulfillment of those needs. The following are the expressions of some participants.

"It's not good if there is no mom. I like mom to accompany me to eat, take medicine, sleep...." (P2)

"When peeing ... with mom, everything is with mom..." (P5)

"No. If father is not there, that ... who wants to help me pee? Is it the nurse?" (P6)

"Early in the morning, she (mom) wakes me up to eat breakfast and feeds me." (P9)

\section{Discussion}

Atraumatic care is a therapeutic care service provided by nurses using interventions that can eliminate and minimize the experience of psychological and physical distress in children and families during the healthcare process. ${ }^{13}$ One of the principles of applying atraumatic care is family-centered care. Family-centered care aims to prevent, reduce, or decrease the impact of the separation of children from parents by involving parents in every childcare action and allowing parents to accompany the child for 24 hours during hospitalization. 14

Childcare room Building A, first floor, has implemented the principle of familycentered care, where there is no time limit for parents to accompany their children in the treatment room. Participants revealed that nurses' actions that allowed parents to accompany children during the treatment process were considered by participants as one form of nurses' kindness towards participants.

From the result of this study, the role of parents in family-centered care partly substitutes that of nurses in delivering care to the patient during the treatment process. Parents not only accompany their children but also help in the children's care, such as administering medication, checking vital signs, and fulfilling the children's basic needs. This finding shows that atraumatic care is provided by not only the nurse but also the parents. Parental presence can minimize the experience of psychological and physical distress in children. Parental presence becomes one of the important needs of the parent during the period of their child's hospitalization. 15
The condition of hospitalization, which has a lot of stressors, causes children to experience stress easily. The stressors that make children feel scared and anxious when undergoing hospitalization are the installation of the IV line and blood collection. ${ }^{16,17}$ Participants in this study said that the installation of an IV line is the most disliked thing during the treatment process. Some participants said that they cried and even felt angry at the nurse due to the pain they felt. This condition caused the children to search for comfortable coping strategies through their parents' presence.

Nurses are responsible for the pharmacological and non-pharmacological management of invasive pain. ${ }^{18}$ However, the results of this study indicate that non-pharmacological pain management is believed to be more effective for children if it is conducted by parents. Parents' can create distractions by playing videos, calming through speech, and touching or hugging the children. Participants expressed that such actions reduced the anxiety and fear that children feel when undergoing invasive procedures.

When undergoing hospitalization, the presence of parents can be a source of motivation and strengthen children to undergo each treatment procedure. ${ }^{19}$ Motivation and explanation given by the parents will make the children calmer and more psychologically prepared. 20 The participants in this study recount that they need their parents' presence round the clock during the hospitalization. The participants said that during the invasive procedure, the presence of parents makes them feel more comfortable and braver. Some of the participants also said that even though they still feel the pain, the intensity is lessened by their parents' touch and hug.

Normally, the psychological development phase of school-age children is already able to control and understand personal emotions. However, the feeling that they are in a difficult or unfamiliar social condition can cause children to be aggressive or self-alienated. 21 The family is the best solution for overcoming these and other difficulties faced by children. A close relationship between a child and their family can be a coping mechanism for children facing difficult situations. 22

Participants in this study recount that the presence of parents can be an entertainer for children undergoing treatment. Limited activities during hospitalization can cause children to feel bored. 23 Through the presence of parents, children feel they have friends to share stories and play with so that the feeling of boredom is reduced.

A study conducted by Boucher among children with a cancer diagnosis suggests that high anxiety and fear cause such children to tend to be loners. ${ }^{23}$ However, based on the study the researchers carried out, the presence of parents enables the child to tell stories and share feelings. This finding is similar to the position expressed by participant 3 that with the accompanying parents, every uncomfortable child can always communicate well.

The presence of parents can not only make children feel safe and comfortable but also provide the opportunity for children to interact. As expressed by participant 7, parents become friends for the children to chat with every day to reduce boredom due to hospitalization. Besides, participant 10 also disclosed that he felt lonely and worried about his condition if his parents did not accompany him during the hospitalization.

One of the roles of parents is to actively participate in the childcare process, which aims to stimulate the growth and development of children. ${ }^{24}$ Some participants in this study recounted that during their hospitalization, the parental presence was very important for the process of care. Parents not only accompany their children but also participate in caring for them. Parents also help hospitalized children to fulfill their basic daily needs, such as eating, taking medicine, bathing, and sleeping.

In line with Maslow's hierarchy of needs theory, psychological needs, such as nutrition, elimination, rest, sleep, and avoidance of pain, are the most important basic needs to be fulfilled for pediatric patients. ${ }^{25,26}$ The Healthcare Commission emphasizes that every adult and child health service must pay attention to the psychological and psychosocial needs of patients. ${ }^{14,27}$ These needs are to be considered as part of the provision of a holistic health service.

\section{Conclusions}

The presence of parents in implementing atraumatic care has a positive impact on children during hospitalization. Every hospital needs to review related policies in facilitating the presence of parents for children during hospitalization. This review is to support effective coping by children and fulfill their holistic psychological needs.

\section{References}

1. Statistics Indonesia (BPS). Profil kesehatan ibu dan anak 2015. Statistics Indonesia. Report Number: 4203002, 2016. Available from: https://www. bps.go.id/publication/2016/12/20/1464 
6448c68db5af30735247/profil-kesehatan-ibu-dan-anak-2015.html

2. Coyne I. Children's experience of hospitalization. J Child Health Care 2006;10:326-36.

3. Rokach A. Psychological, emotional, and physical experiences of hospitalized children. Clin Case Rep Rev 2016:2:399-401.

4. Wen KY, Gustafson DH. Needs assessment for cancer patients and their families. Health Qual Life Outcomes 2004;2:1-12.

5. Favara-Scaco C, Smirne G, Schiliro G, Di Cataldo A. Art therapy as support for children with leukemia during painful procedures. Med Pediatr Oncol 2001;36:474-80.

6. Supartini Y. Buku ajar: Konsep dasar keperawatan anak. Jakarta: EGC; 2014.

7. LeVieux-Anglin L, Sawyer EH. Incorporating play interventions into nursing care. Pediatr Nurs 1993;19: 459-63.

8. Ahmann E. Promoting positive parenting: An annotated bibliography. Pediatr Nurs 2002;28:382-5.

9. Sukhodolsky DG, Cardona L, Martin A. Characterizing aggressive and noncompliant behaviors in a children's psychiatric inpatient setting. Child Psychiatry Hum Dev 2005;36:177-93.

10. Mittal V. Family-centered rounds. Pediatr Clin North Am 2014;61:663-70.

11. Vasquezs R. Interviewing children: Excerpts from an article for Court Appointed Special Advocates to help professional evaluators interview children; 2000. Available from: http://www. hunter.cuny.edu/socwork/nrcfcpp/down loads/Interviewing_Children_0508.pdf

12. Creswell JW. Qualitative inquiry \& research design choosing among five approaches. 3rd ed. California: SAGE Production; 2013.

13. Wong DL, Hockenberry MJ, Marylin J. Wong's nursing care of infants and children. St. Louis, Missouri: Mosby Inc.; 2009.

14. Salmela M, Salantera S, Aronen ET. Coping with hospital-related fears: Experiences of pre-school-aged children. J Adv Nurs 2010;66:1222-31.

15. Apriyanti E, Adawiyah R. Kebutuhan keluarga saat anak dirawat di Paediatric Intensive Care Unit (PICU): Sudut pandang keluarga dan perawat. Jurnal Keperawatan Indonesia 2018;21:159-68.

16. Bowden VR, Dickey, SB, Greenberg, SC. Children and their families: The continuum of care. Philadelphia: W.B. Saunders Company; 2010.

17. Kennedy RM, Luhmann J, Zempsky WT. Clinical implications of unmanaged needle-insertion pain and distress in children. Pediatrics 2008;122: 130-3.

18. Ellis JA, Sharp D, Newhook K, Cohen, J. Selling comfort: A survey of interventions for needle procedures in a pediatric hospital. Pain Manag Nurs 2004;5:144-52.

19. Feo R, Kitson A. Promoting patientcentred fundamental care in acute healthcare systems. Int J Nurs Stud 2016; 57:1-11.

20. Hockenberry JM, Wilson D. Wong's essentials of pediatric nursing. 8th ed. London: Elsevier; 2009.

21. Anthony M. The emotional lives of 8 10-year-olds. Available from: https:// www.scholastic.com/parents/familylife/social-emotional-learning/development-milestones/emotional-lives-8-10year-olds.html [Accessed 25th June 2019].

22. Coleman W ed., Elias E ed., Feldman H ed., et al. Developmental-behavioral pediatrics. 4th ed. Philadelphia: Elsevier; 2009.

23. Boucher S, Downing J, Shemilt, R. The role of play in children's palliative care. Children 2014;1:302-17.

24. Lifecho. What is the role of parent? The roles of being a parent. Available from: http://www.lifecho.com/what-is-therole-of-a-parent-roles-of-being-a-parent/ [Accessed 15th June 2019].

25. Kozier B, Berman A, Shirlee J. Buku ajar fundamental keperawatan konsep proses dan praktik edisi VII. 1st ed. Jakarta: EGC; 2011.

26. McLeod S. Maslow's hierarchy of needs; 2018. Available from: https://www.simplypsychology.org/mas low.html [Accessed 25th June 2019].

27. Royal College of Psychiatrists' Centre for Quality Improvement. The national audit of violence 2006-7: Final reportworking age adult services. Healthcare Commission 2007:1-157. 